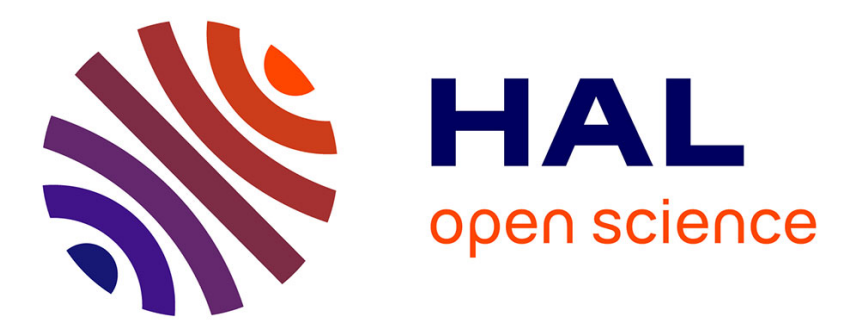

\title{
Using Serious Gaming to Discover and Understand Distributed Ledger Technology in Distributed Energy Systems
}

\author{
Jan W. Veeningen, Nick B. Szirbik
}

\section{- To cite this version:}

Jan W. Veeningen, Nick B. Szirbik. Using Serious Gaming to Discover and Understand Distributed Ledger Technology in Distributed Energy Systems. IFIP International Conference on Advances in Production Management Systems (APMS), Aug 2018, Seoul, South Korea. pp.549-556, 10.1007/9783-319-99704-9_67. hal-02164900

\section{HAL Id: hal-02164900 https://hal.inria.fr/hal-02164900}

Submitted on 25 Jun 2019

HAL is a multi-disciplinary open access archive for the deposit and dissemination of scientific research documents, whether they are published or not. The documents may come from teaching and research institutions in France or abroad, or from public or private research centers.
L'archive ouverte pluridisciplinaire HAL, est destinée au dépôt et à la diffusion de documents scientifiques de niveau recherche, publiés ou non, émanant des établissements d'enseignement et de recherche français ou étrangers, des laboratoires publics ou privés.

\section{(c)(1)}

Distributed under a Creative Commons Attribution| 4.0 International License 


\title{
Using Serious Gaming to Discover and Understand Distributed Ledger Technology in Distributed Energy Systems
}

\author{
Veeningen, J.W. ${ }^{1}$ and Szirbik, N.B. ${ }^{1}$ \\ ${ }^{1}$ University of Groningen, Groningen, The Netherlands \\ $\{j \cdot w . v e e n i n g e n @ s t u d e n t . r u g . n l ; n . b . s z i r b i k @ r u g . n l\}$
}

\begin{abstract}
This paper provides an extension to a family of games that are in the theme of distributed energy systems. This extension of the family of games is a direct result of developing a derived type of game, that is, an energy trading and investing game that involves the infrastructural usage of a new technology, in this particular case, blockchain (a type of distributed ledger technology). The game's novel architecture is explained succinctly, and some results are discussed. Shortly, the extensions of the generic architecture are listed, and special emphasis is put on the idea that such a game must have a two-phased play - one with the novel technology not active and one with it activated. Finally, some insights in game architecture development and the necessary next steps are posited.
\end{abstract}

Keywords: Serious games, blockchain, renewable energy.

\section{Introduction}

To keep up with the latest innovation trends and remain competitive, companies should continuously be aware of novel technologies that can impact their processes and decide whether they should adapt and use those emerging technologies. Nevertheless, technology-driven trends are sometimes irrelevant for certain industrial domains. One of the researcher's challenge is to make an early context-dependent distinction between new valuable technologies from irrelevant ones for specific and generic cases of application. Many times, new technologies have often had quite different effects that initially expected. A classic example is the steam machine, initially envisaged an applied to pump water out of mines; creative people adapted it quickly for transporting goods and people. Another relevant example is the early digital DARPANet which was intended for military command, control, and intelligence (C2I); nowadays the civilian version of the Internet and its applications are used to bring people close for personal and social goals, business and commerce, entertainment and politics. However, the stakeholders who are responsible of taking the decision to use the novel technologies with positive disruptive potential are not always convinced of the benefits of their adoption. In some cases, a healthy skepticism is welcome, because more than many technology-driven "silver-bullets" did not deliver, leaving stakeholders burdened with huge investments that never paid off. A relatively recent (2012) example is Google Glass and its promise 
to revolutionize how social networks will work in the future. Although the technology itself was working and up to the promised task, concerns about the privacy of others (nobody likes to be recorded without their knowledge), price (around \$1500) and copyright infringement (in movie theaters), kept the device from going mainstream, though it is still used in some professional applications. A simple way to make the stakeholders in a certain domain aware about the implications of a new technology is to show the impact of this technology on the business processes via a serious game. This paper shows how a novel technology trend can be included in the architecture of serious games, and how such games can be used to make players/stakeholders aware and understand these technologies. The next section presents the novel technology trend, section 3 presents how a serious game can be used to increase stakeholder trust in certain aspects of a complex business process, section 4 illustrates the application of a novel technology to energy markets, section 5 explains how an existing generic architecture for serious games was extended, section 6 comments on the preliminary results, and section 7 concludes the paper.

\section{$2 \quad$ Distributed ledger technology as a novel trend in various domains}

A technology trend that is currently in its ascent phase is the distributed ledger technology (DLT) called blockchain [1], which enables some currently popular (albeit controversial) cryptocurrencies like Bitcoin. DLT is a technology that entails a record of information (a database), that is shared across a network. In a blockchain-based system, all transaction data is multiply stored in blocks that are attached to each other to form a chain. The transactions in the system are continuously reviewed by a fixed number of independent members, which opens the possibility that intermediaries who are centrally organized and trusted are not any more necessary. For example, in processes like payments, clearings, and settlements, blockchain technology offers a decentralized solution for storing data in a secure, verifiable, and trustworthy way [2].Due to the hype it generated, many different businesses are interested in the technology, but they do not understand the possibilities of the technology or are wary or even afraid to invest for its implementation. In Europe, various industries like finance, education, logistics, the energy industry and also individual companies are exploring the possibilities for applying DLT in their business [3]. For example, the European Central Bank published an exploratory paper [4] about possible use cases in security markets, suggesting several scenarios, and recognized that DLT holds potential for the financial industry. Another immediate and already adopted application is in supply chains of products that are sensitive to tampering, like second-hand cars, where the mileage and maintenance status of the car is essential for trust [5]. Researchers also point out that one of the biggest potential application of blockchain technology is in the area of smart contracts, that is a self-executing contract that can be used as an alternative to enforcement, and does not need the intermediaries like e-commerce sites, credit card companies, or courts [6]. This raises the possibility to have peer-to-peer contracts in a decentralized energy market, where consumers are sometimes producers and vice-versa. To see where DLT can be 
of an added value requires a better understanding and more awareness of the potential applications of DLT. The authors of this paper consider that serious games can be one of the solutions that can bring awareness, understanding, and the ability to think of new applications for a specific technology in a given industrial context.

\section{$3 \quad$ Raising stakeholders' trust and understanding with a serious game for peer-to-peer distributed energy systems}

The authors' previous research involved the building of and experimenting with serious games in relation to various infrastructural inception problems like the development of a bio-gas infrastructure in the Netherlands, and also the development of local smallscale demand and supply infrastructure for wind power. The need to quickly prototype games led to the development over years of a game generic architecture and the guidelines to apply it for a given context [7]. This architecture is considered a constant work in progress, as an artefact of design science at work, trial and error, and refinement. This generic architecture has a primary purpose for the games developed from it, that is, to convince stakeholders that investing in a multi-player inception infrastructure brings rewards in the long term. Typically, there is a blockage in this kind of investments, because all stakeholders wait for the others to make the first move. For example, in an variant of the game where LNG-powered truck-refueling infrastructure was envisaged, the truck fleet owners waited for the stations owners to develop new stations, and station owners waited that truck fleet owners acquire more LNG-powered trucks. Stakeholders like investors, LNG distributors, customers who wanted a "green logistic" image were not even factored in this "chicken and egg" problem mitigation. The game could bring together all these stakeholders and show them that various long term scenarios can be discovered via game playing, where all stakeholders ended in a win-win outcome. A new step forward towards the extension of the generic architecture of this kind of games that was done recently, via implementing a new kind of game, i.e. the "blockchain within local energy" game. Here, the main purpose of the game is not the discovery of win-win scenarios of investment and return of investment. The goal is to make stakeholders adopt a novel technology. The previous experiences with the afore mentioned games hinted that serious gaming is potentially helpful in understanding possibilities of new technologies. In the bio-gas game [8], the main goal was to gain insights in the factors that contribute to success or failure in the complex and difficult investment processes for the gas and bio-gas infrastructure in The Netherlands. Nevertheless, the players (who were technical and non-technical stakeholders in the gas industry) became aware and understood the finer points related to the technological details of the infrastructure. In a mere presentation of the technologies involved, the stream of information was unidirectional and the listeners often forget what was presented. With serious gaming, the technology was "experienced" and discussed between the players engaged in the game. Extant literature also supports this finding, it has been confirmed that a game is beneficial for learning knowledge that is considered outside the normal expertise of a player [9]. 


\section{$4 \quad$ Distributed Ledger Technology in Distributed Energy Systems.}

A promising use case for DLT is in the energy industry. This is because the popularity of distributed energy resources (DERs) is rising. This is enforced by the fact that solar and storage technology is decreasing in price and becoming more available for households. Blockchain, by its nature, allows that the systems can be organized and coordinated in a decentralized manner. Thus it fits the decentralized organization of the energy infrastructure discussed. There are many systems in the energy industry where the infrastructure is organized in a decentralized manner, some already supported by blockchain technology. In Brooklyn, NY, an initiative [10] was taken by a community which organized a local market where electricity is exchanged. In this community, households owning solar panels are able to sell electricity to other members of the community, so they can keep trading profits within the community. This incentivizes and simplifies the process of investing in now solar panels, wind turbines, or local energy storage, simply because the community members no longer have to pay for the service of an intermediary. The transaction system is based upon blockchain technology, where the participants pay each other with a local cryptocurrency. Another example, which is a global initiative, where incentives facilitated by DLT are provided for solar powered energy is SolarCoin $[11,12]$. This is a special kind cryptocurrency that since January 2014 is distributed amongst owners of solar panels that are located anywhere in the world, even off-grid. The goal of the creators of the coin is to incentivize generating renewable energy and to that end, they give 1 SolarCoin to people for every MWh that they produce with their solar panels. Later, these producers will be able to exchange SolarCoins as consumers of other green and ethical goods made available for trading with this currency, invest in new production capacity created by SolarCoin buyers, donate for charity, etc. At the time of writing this text, there were 6,980,342.4 SolarCoins granted to solar energy producers in 59 out of the world's 215 countries. Nevertheless, the application of the blockchain technology in energy can be segmented in local, private blockchain applications - which can interact with cryptocurrencies like SolarCoin (but not necessarily). In the Netherlands, in Amsterdam, a pilot project [13] was initiated by a collaboration between De Ceuvel, Alliander, and Spectral. In this project, locally produced renewable energy is distributed in a community supported by blockchain technology. Participants of the system can trade energy from peer to peer and handle transactions via a specially created cryptocurrency. These examples show that companies are actively searching for blockchain technology applications in redesigning energy infrastructures. To make potential participants in such a complex system more aware of the benefits of DLT, it was considered that a serious game could make them discover the benefits. Moreover, playing this game together with the participants, new use cases could be discovered. What the initial attempts for gaming also show is that there are numerous parties that are very willing to deploy such a blockchain enabled micro-grid. However, some of these stakeholders are not yet convinced, and the intention is that the game playing helps them to get in touch with the blockchain technology and its usefulness in the DER context. 


\section{The specific features of the DLT energy game}

The blockchain energy game is designed simulate an energy exchanging community that consists out of households of which some own solar panels or wind power microplants. The owners of the electricity producing units may consume the output themselves, however when they have a surplus they want to sell it to the existing grid. The main problem in this scenario is that price they get for their produced electricity is fixed and quite lower than the two fixed prices (peak and through prices) that are currently offered in the energy retail contracts. Moreover, the selling price can be perceived by these prosumers as ridiculously lower in comparison with the volatility prices that appear on the higher level spot-market managed by the grid (energy prices can go 100 times over the average when the demand is high). However, retail contract participants cannot play on this spot-market, which is only for specialized traders who trade on the supply and demand of high-volume producers and users (trading kilowatts vs trading megawatts) This inability to participate in the higher level market where prices are dynamic, and profit can be made during high demand period, reduces the incentive to invest in extra producing capacity. The grid operator has the responsibility to maintain grid stability and provide a reliable power supply. Traditionally, the electricity supply was a one-way stream, but nowadays distributed reusable energy resources are gaining popularity. However, solar and wind produced electricity which puts power back on the grid creates instability and it becomes nowadays a challenge for grid operators. The game is to be played in two distinct phases: the first phase is the current real-world situation with limited selling prices for produced electricity to the grid and increasing instability of the grid due to DERs. In the second phase the blockchain technology is introduced and this enables an energy exchanging community. Peer-to-peer trading, smart contracts, and transactional transparency are introduced. In both phases, households have the option to invest in solar panels, wind micro-plants, and also electricity storage units. In the first phase, the households with solar panels will consume their own produced electricity and they will want to sell their surplus to the utility company. However, they will receive a very low fee for every kWh they want to sell. Thus, investing in a collection of solar panels that has a capacity that is higher than their own consumption is not attractive. The attractiveness of (extra) production capacity and eventual storage is linked to the consumption of the households and to the producing capacity. The higher the consumption of the household and its storage capability, the higher the capacity needed to meet this demand - and the potential to sell energy to the grid, albeit this is constrained by un-attractive low and fixed prices.

When the second phase begins, the ability to sell energy to neighbors at dynamic prices will be given to the households that own production capacity. A solar panel owner without storage can sometimes sell its surplus to neighbors at a better price than selling it to the grid. This incentivizes investment in extra solar panels in the energy exchanging community. The equilibrium of such a community would be when there are enough solar panels to be self-sufficient within the community. The grid instability that arises with the increasing nationwide popularity of DERs can be diminished by establishing 
such a community. That is, within the community the frequency and load of the network will be managed separately from the normal grid. This enables further an increasing number of DERs, while maintaining stability. When the self-sufficiency of the community increases, the distance that power has to travel before it can be consumed also decreases significantly. Investment in local storage allows players to choose the right time to sell the excess energy, for a better price. The game is purposefully designed to show the difference of the situation ex-ante and ex-post blockchain implementation. Players will notice that the price they are able to sell their energy for is much higher than before. The payback period of the return of the investment in producing units for solar and wind decreases significantly and investing in more power capacity is therefore incentivized. The previous papers $[7,8]$ showed games where an infrastructure is developed to enable local exchanges between producers, transporters, storage owners, and consumers of electricity or biogas. In this novel game, exchanges of electricity are also played, but now these exchanges are supported by blockchain technology which allows for a novel manner to register and manage transactions. The new game extends the existing generic architecture of energy trading games with a new set of functions and guidelines, that will be applied when the game should include the adoption of a new technology (which is not blockchain necessarily).There are a few new aspects that appear in the upgraded architecture. First, the main goal of the game is that a new technology is communicated via the game. The balance between showing the application and the inner workings has to be carefully thought of. Too much showing the inner workings of blockchain would not serve the purpose of understanding the applications of the new technology on a more meta level. In this particular example, the possibility to record in a trustworthy and immutable manner all the transactions between participants explains actually how the price calculations and settlements between participants can be done securely and fair for all. Second, the game has first to be played without the novel technology to show the status quo and only then starting the game over from the initial situation - but now with the technology "enabled". This shows clearly to the stakeholders the difference in the outcomes with and without the technology. Finally, all the "commercial" information is communicated to a "blockchain" and this is used to enable visual feedback for the players and control against cheating. This last aspect is less generalizable, but the idea for the generic architecture is that visual tools should be used to show the impact of the technology and also give hints about how it works and how it is applied in the context.

\section{$6 \quad$ First results and next steps}

After the first test run of the game, feedback was collected for improving the game and the guidelines for serious game creation. The game showed to be able to start up conversation and thought about the new technology and how it can be applied in society. Understanding and awareness of the application of blockchain in distributed energy systems were both increased. The players could clearly see how solar panel owners in the current situation are not incentivized to invest in more solar capacity because of the 
low profits realized by selling their solar power. When DLT was enabled, the community of households could exchange energy internally. This showed that DLT can act as a catalyst for the energy transition by incentivizing DER investments. For the next steps in developing the game, a second technology, that is, energy storage should be included not a as mere investment, but as an enabling technology (like blockchain in the first experiment). Efficient and long lasting electric power storage at its current prices (\$400 per installed $\mathrm{kWh}$ ) is considered not attractive economically to invest in, even in a community setting. However, the costs per installed kWh storage are expected [14] to drop significantly in the coming years - especially due to economies of scale, which is also simulated in the game. Positive practical examples are seen in Texas [15], where storage is now continuously installed to balance the intermittency of the fast-growing local wind power generation, and in Australia, where recently Tesla exceeded expectations with a large-scale storage project [16]. This opens the expansion of the generic architecture of this kind of games to not only one technology in a game setting, but to two or more technologies that enable the investments or even catalyze the use and expansion of each other in a cascading effect.

\section{Conclusions}

The game sessions played strongly support the assertion that beside the well-known results, a serious game can also be used to increase the understanding and awareness of new infrastructure system stakeholders about new technologies, such as blockchain. This is an interesting finding, even more stringent today, as companies need to keep up with new ideas, innovations, and technologies that appear and evolve at an increasing pace - like for example, the Physical Internet [17]. The main message of this paper is that a new game can be built easier based on the generic architecture proposed and expanded to increase understanding to enable discovery of new applications of technologies or how they can be applied in certain industries. The paper has shown through the example of the two distributed energy system games that it is possible to develop a generic game architecture. The two successive development of novel games, on top of the same generic architecture, helped to further this architecture into a new dimension, that is, the technological one.

\section{References}

1. Stefan K. Johansen. A comprehensive literature review on the Blockchain as a technological enabler for innovation. Technical report preprint, Mannheim University. (2018)

2. David C Mills, Kathy Wang, Brendan Malone, et al. Distributed ledger technology in payments, clearing, and settlement. https://www.federalreserve.gov/econresdata/feds/2016/files/2016095pap.pdf. (2016)

3. Marc Pilkington. 11 blockchain technology: principles and applications. Research handbook on digital transformations, page 225. (2016) 
4. Andrea Pinna and Wiebe Ruttenberg. Distributed ledger technologies in securities posttrading revolution or evolution? https://www.ecb.europa.eu/pub/pdf/scpops/ecbop172.en.pdf. (2016)

5. Kei-Leo Brousmiche, Thomas Heno, Christian Poulain, Antoine Dalmieres, and Elyes Ben Hamida. Digitizing, Securing and Sharing Vehicles Life-cycle Over a Consortium Blockchain: Lessons Learned, in IFIP NTMS Blockchain and Smart Contracts Workshop. (2018)

6. Riikka Koulu. Blockchains and Online Dispute Resolution: Smart Contracts as an Alternative to Enforcement. SCRIPTed: A Journal of Law, Technology, and Society, 13:40-69. (2016)

7. Jan Willem Veeningen, Nick Szirbik, and Marco Blokhuis. A Generic Architecture for Quickly-Deployable, Flexible, Scenario-Oriented Serious Games. Conference Paper in APMS 2017: Advances in Production Management Systems. The Path to Intelligent, Collaborative and Sustainable Manufacturing. (2017)

8. George Huitema, Nick Szirbik, Hans Wortmann, Ashwin Ittoo, and Austin Dzousa. Embedding flexibility in combined gas and electricity infrastructures. In 4th Research Day EDGaR. (2012)

9. Ivo Wenzler. Is your simulation game blue or green. Caluwé, L de, G. Hofstede \& V. Peters. Why do games work. In search for the active substance. (2008)

10. Esther Mengelkamp, Johannes Gärttner, Kerstin Rock, Scott Kessler, Lawrence Orsini, and Christof Weinhardt. Designing microgrid energy markets: A case study: The Brooklyn microgrid. Applied Energy, 210:870-880. (2018).

11. Luke Patrick Johnson, Ahmed Isam, Nick Gogerty, and Joseph Zitoli. Connecting the blockchain to the sun to save the planet. (2015)

12. Nick Gogerty and Joseph Zitoli. Deko: An electricity-backed currency proposal. (2011)

13. Pilot project Jouliette at de Ceuvel, Amsterdam. https://jouliette.net/blockchain.html. (2018)

14. International Renewable Energy Agency. Electricity Storage and Renewables: Costs and Markets to 2030. (2017)

15. https://www.bloomberg.com/news/articles/2017-12-07/u-s-energy-storage-surges-46-ledby-big-project-in-windy-texas. (2017)

16. https://www.nytimes.com/2017/11/30/world/australia/elon-musk-south-australia-battery.html. (2017)

17. Henrik Sternberg and Andreas Norrman, The Physical Internet - review, analysis and future research agenda. International Journal of Physical Distribution and Logistics Management, 47/8:736-762. (2017) 